\title{
A seven-year study about the epidemiology of smoking, alcohol, drugs and psychotropic consumption along with legal abortion in cases referred to forensic medicine centers in Fars since 2007-2013
}

\author{
Ghodrati $F^{1}$, Saadatmand $N^{2}$, Zarenezhad $\mathbf{M}^{3}$, Akbarzadeh $\mathbf{M}^{4}$ \\ ${ }^{1}$ Fatemeh Ghodrati, Department of Theology, Faculty of Humanities Science College, Yasouj University.Yasouj. Iran. \\ ${ }^{2}$ Narges saadatmand, Department of Midwifery, Student Research Committee of Shiraz, Gachsaran Branch, Islamic Azad \\ University, Gachsaran.Iran. ${ }^{3}$ Mohammad Zarenezhad, Legal Medicine Research Center, Legal Medicine Organization, \\ Tehran, Iran. ${ }^{4}$ Marzieh Akbarzadeh, Maternal -Fetal Medicine Research Center, Department of Midwifery, School of \\ Nursing and Midwifery, Shiraz University of Medical Sciences, Shiraz, Iran.
}

Address for Correspondence: Maternal -fetal Medicine Research Center, Department of Midwifery, School of Nursing and Midwifery, Shiraz University of Medical Sciences, Shiraz, Iran. E-mail: akbarzadm@sums.ac.ir

\begin{abstract}
Introduction: Smoking, alcohol, and drugs consumption has increased among the women of child-bearing age. This rise and its negative consequences on the children's health have been considered by planners and WHO health centers. This study aimed to examine the prevalence of smoking, alcohol and drugs consumption among women of childbearing age who received abortion permission with either maternal or fetal causes from forensic medicine centers. Method: This is a descriptive-analytical study which was conducted during the years 2007-2013. The total sample size was 1,664, of which 339 and 1325 had maternal and fetal abortion causes, respectively. The items registered in the questionnaire included demographic and obstetric variables, maternal or fetal causes of abortion, the simultaneous use of hookah and cigarettes, alcohol, psychotropic substances and drugs. The data were analyzed using descriptive statistics in SPSS software, version 11.5. Results: The most frequent age for women was between 25 and 30 years $(31.5 \%)$. The legal abortion rate was $8.5 \%$ among women aged under 20 years old. The prevalence of substance consumption was $40.7 \%$ among women with either maternal or fetal cause abortion. It was estimated that $78.3 \%$ belonged to cigarette and hookah, $14.62 \%$ to drug and psychotropic and finally 5.31\% to alcohol beverage consumption. Conclusion: In Iran, legal abortion approval is either by maternal or fetal causes. According to this study, the coincidence of pregnancy with cigarette and hookah consumption has the most prevalence. Substance abuse prevention, treatment, and control policy are one of the essential matters related to the care both before and during pregnancy.
\end{abstract}

Keywords: Abortion, Alcohol, Cigarettes, Drugs, Psychotropic.

\section{Introduction}

Women's health is not only the issue of human right but also its impression on family and society health is notable [1-2]. The prevalence of pregnancy in the world is about 180 million cases annually [3]. Despite the high ratio of natural birth ( 96 percent), even a subtle neglect can endanger both maternal and fetal health [4].

Manuscript received: $7^{\text {th }} \mathrm{Feb} 2016$

Reviewed: $15^{\text {th }}$ Feb 2016

Author Corrected: $25^{\text {th }}$ Feb 2016

Accepted for Publication: $13^{\text {th }}$ March 2016

International Journal of Medical Research and Review
Women's fertility and their maternal role functions can mainly affect the women's health. The long-term health of women and their family members (particularly children) is associated with their health in the childbearing age [4].

Natural fertility formation requires maternal biological maturity, immunity against preventable diseases, control of metabolic and chronic disorders, timely care and sufficient nutrients [5]. Many of pregnancy risk 
factors can seriously threaten the health of the mother and fetus. Addictive substance abuse is a social problem during pregnancy, not only for its devastating effects on fetal and maternal health but also for its dependency which leads to fetus and infant care reduction and family breakdown [6].

Drug consumption during pregnancy is the common concern among health officials around the world. It leads to prenatal complications, cognitive defects, and disorders. There are a constant change and controversy about drugs (such as tobacco, alcohol, cocaine, heroin) exposure implications in the literature [7]. Crime United Nations and Counter Narcotics Office reported that drug consumption is increasing in 2011. They announced nearly 16 million people as the prevalence rate of opium consumption [8]. According to American Academy of Pediatrics and American College of Obstetricians and Gynecologists surveys in 2012, at least $10 \%$ of the embryos are exposed to one or more types of the drugs [9].

According to the review study which was conducted by Department of Mental Health Research and National Research Center of Medical Sciences, opioid-addicted women are estimated at 100 to 150 thousand people in Iran. The number of women who inject drugs is estimated to be between 4 and 9 thousand. Besides, the real concern is about the increasing number of heroinaddicted women [10]. Another study estimated the number of opioid-addicted pregnant women as $1.4 \%$ in Iran [11].

Deputy Head of Iran's anti-narcotics organization reported an increase of $15 \%$ in the addicted women death cases. They also announced that women constitute 3.9 percent of the drug addicted population. The statistics show an increase of $16 \%$ in the population of deadly addicted women from 2012 to 2013. "The adverse results of drug abuse include domestic violence $(65 \%)$, divorce (55\%), child abuse (30\%), death (25\%), quarrel and violence $25 \% "[12]$.

Some studies aimed to describe the prevalence of substance use among pregnant women and its association with complications during pregnancy, delivery, postpartum and fetus and baby health in Czechoslovakia. In 2000-2009, 1,008,821 mothers were reported to have delivery, out of which 60502 were recorded as cigarette smokers, 1528 as alcohol users and 1836 as other illegal substances. The direct relationship was found between substance use and fetal abortion only in smokers. The probability of drastic complications in smoker mothers-, illicit drug users, and alcohol abusers was reported as $40 \%, 13 \%$, and $5 \%$, respectively.

The study indicated no any association between substance use and problems during childbirth. Alcohol and illegal drugs use was along with the rise in the probability of puerperium complications. There was a significant negative correlation between fetal/newborn health and cigarette smoker-mothers. Alcoholic mothers during pregnancy were primarily encountered with fetal health status immediately after delivery, congenital anomalies, stillbirth or need for treatment of endangered newborns. The probability of infant hospitalization after discharge, his transfer to infant home and infant death was high among infants of mothers using substance during pregnancy. Therefore, the association between the complications during pregnancy, delivery, puerperium, and health status of newborns and substance use of mothers during pregnancy was found mainly in cigarette smokers. A significant association was reported between alcohol abuse and maternal-fetal health complications (not serious). No any correlation was found between illegal drugs and the indices in this study [13].

Drug abuse leads to preterm delivery, spontaneous abortion, post-partum bleeding, and delivery complications [14]. Long-term effects of exposure to tobacco during pregnancy include miscarriage, ectopic pregnancy, and placental insufficiency in mothers [15]. On the other hand, neonatal complications include low birth weight, intrauterine growth retardation, perinatal deaths, placental abruption, fetal congenital abnormalities, and fetal distress [16-17]. Intrauterine death syndrome, growth restriction, prematurity, stillbirth, neonatal abstinence syndrome and Sudden Infant Death Syndrome are just some of its fetal effects [14].

Moreover, these women are much more vulnerable to the increased risk of medical problems such as malnutrition, anemia, urinary tract infections and sexually transmitted infections, hepatitis, HIV and problems related to infection [14].

The average birth weight of babies born to addicted mothers was $2255 \mathrm{~g}$ which revealed a significant difference by non-addicted mothers ( $\mathrm{P}<0.0001)$. The average APGAR scores at the first minute were $7.6 \pm$ 1.1 and $8.6 \pm 1.1$ among the infants from addicted and non-addicted mothers, respectively [18]. In another study, mother's addiction resulted in asphyxia and 
cerebral, physical problems, lower Apgar score and lower birth weight [18]. Utero-exposure to drugs was along with increased rate of respiratory infections, asthma, ear and sinus infections in childhood.

In addition, these children experience more irritability, difficulty in focusing their attention, and behavioral problems. Therefore, embryo evaluations are significantly necessary to identify those who are in danger, which is in relation with the maternal and infant cares. According to the study which was conducted on 956 cases with fetus abortion at 30 selected clinics in America between 2008-2010; the factors such as ATOD (5\%), wine drinking (84\%) and drug abusing (61\%) accounted for fetal abortion (however, $88 \%$ of drug abusers had the consumption frequency of more than once a week). Two-thirds of tobacco consumers didn't blame tobacco use as the cause of their own miscarriage [19].

According to another study, the intake of caffeine (more than $300 \mathrm{mg}$ daily) both before and during pregnancy results in an increase of abortion rate for $31 \%$. Alcohol consumption both before and during pregnancy leads to increase of spontaneous abortion rate by $30 \%$ (RR 1.30; 95\% CI: 0.85-1.97).

It was found that cigarette smoking is along with almost 3-fold increased risk of congenital heart defects [ 20]. The constant concerns about the effects of alcohol and drug use during pregnancy are always intertwined with the debates about abortion and unwanted pregnancy $[19,21]$.

According to the study which was conducted on opiumaddicted pregnant women in Iran, there was a significant difference in the complications such as: placental abruption, preterm delivery, preeclampsia, premature rupture of membranes, intrauterine growth retardation, vivid fetal malformations, low Apgar score in the first and fifth minutes, and a decrease in weight, height and head circumference among infants born to addicted mothers compared with the control group (non-addicted mothers) [22].

Illegal marriage and previous induced abortion were reported as significant risk factors affecting pregnancy outcomes in women [23]. In our country, the necessity of induced abortion and its approval (before spirit insufflation) goes for the following conditions: maternal health risks, fetal malformation, rape, and intensive poverty based on the evidence, but exactly after spirit insufflation, it will be an absolute prohibition by most jurists. Despite many studies on the philosophy of the necessity of abortion and its ethical approach [24-26], fewer studies have focused on maternal addiction to alcohol, cigarette and opium along with fetal legal abortion.

This study aimed to conduct a seven-year research about the epidemiology of smoking, alcohol, drugs and psychotropic consumption along with legal abortion in cases referred to forensic medicine centers in Fars during the years 2007-2013.

\section{Method}

This was an analytic epidemiological study conducted using cross-sectional approach. The study population consisted of all judicial documents related to personal and legal abortion requests which had been referred to forensic medicine center in Shiraz during the years 1392-1386. The total sample size was 1,664 , of which 339 and 1325 had maternal and fetal abortion causes, respectively. After the approvals process from Shiraz University of Medical Sciences and the Department of Forensic Medicine, all the documents were studied by referring to the Forensic examination centers.

Also, checklists and other pre-compiled questionnaires were accomplished.

The items were registered in the questionnaire including demographic and obstetric variables, and maternal or fetal causes of abortion. The data were analyzed using descriptive statistics in SPSS software - version 11.5.

\section{Results}

The most frequent age for women was between 25 and 30 (31.5\%). The legal abortion rate was $8.5 \%$ among women under 20 years of age (Table-1). 
Table 1: Frequency distribution of legal abortions according to age of mother

\begin{tabular}{|l|c|c|c|c|c|c|c|}
\hline Age & $<\mathbf{2 0}$ & $\mathbf{2 0 - 2 5}$ & $\mathbf{2 5 - 3 0}$ & $\mathbf{3 0 - 3 5}$ & $\mathbf{3 5 - 4 0}$ & $\mathbf{> 4 0}$ & Total \\
\hline Frequency & 142 & 445 & 524 & 309 & 175 & 69 & 1664 \\
Percent & 8.5 & 26.75 & 31.5 & 18.6 & 10.5 & 4.15 & 100 \\
\hline
\end{tabular}

The most frequency for abortion approval was reported among those below 20years old (14.6\%) in 2012, 20-25-year-old (38.27\%) in 2007. The abortion frequency in 25-40-year-old mothers was 36\%, 22.2\%, and 20.2\%, respectively in 2000 . (Table-1).

Table 2: Frequency distribution of legal abortion according to maternal age since 2007 to 2013

\begin{tabular}{|c|c|c|c|c|c|c|c|c|}
\hline & \multirow[b]{2}{*}{ Year } & \multicolumn{6}{|c|}{ Maternal Age } & \multirow{2}{*}{ Total } \\
\hline & & $20>$ & $20-25$ & $25-30$ & $30-35$ & $35-40$ & $40<$ & \\
\hline 2007 & $\begin{array}{c}\text { Frequency } \\
\text { Percent }\end{array}$ & $\begin{array}{c}5 \\
(6.17)\end{array}$ & $\begin{array}{c}31 \\
(38.27)\end{array}$ & $\begin{array}{c}19 \\
(23.45)\end{array}$ & $\begin{array}{c}17 \\
(21)\end{array}$ & $\begin{array}{c}5 \\
(6.17)\end{array}$ & $\begin{array}{c}4 \\
(4.93)\end{array}$ & $\begin{array}{c}81 \\
(100)\end{array}$ \\
\hline 2008 & $\begin{array}{c}\text { Frequency } \\
\text { Percent }\end{array}$ & $\begin{array}{c}24 \\
(10.43)\end{array}$ & $\begin{array}{c}76 \\
(33.04)\end{array}$ & $\begin{array}{c}60 \\
(26.1)\end{array}$ & $\begin{array}{c}44 \\
(19.13)\end{array}$ & $\begin{array}{c}18 \\
(7.82)\end{array}$ & $\begin{array}{c}8 \\
(3.47)\end{array}$ & $\begin{array}{c}230 \\
(100)\end{array}$ \\
\hline 2009 & $\begin{array}{c}\text { Frequency } \\
\text { percent }\end{array}$ & $\begin{array}{c}30 \\
(8.7)\end{array}$ & $\begin{array}{c}122 \\
(35.7)\end{array}$ & $\begin{array}{c}102 \\
(29.82)\end{array}$ & $\begin{array}{c}56 \\
(16.4)\end{array}$ & $\begin{array}{c}20 \\
(5.85)\end{array}$ & $\begin{array}{c}12 \\
(3.5)\end{array}$ & $\begin{array}{c}342 \\
(100)\end{array}$ \\
\hline 2010 & $\begin{array}{c}\text { Frequency } \\
\text { percent }\end{array}$ & $\begin{array}{c}20 \\
(5.8)\end{array}$ & $\begin{array}{l}34 \\
(7)\end{array}$ & $\begin{array}{c}120 \\
(34.6)\end{array}$ & $\begin{array}{c}77 \\
(22.2)\end{array}$ & $\begin{array}{c}70 \\
(20.2)\end{array}$ & $\begin{array}{c}26 \\
(7.5)\end{array}$ & $\begin{array}{c}347 \\
(100)\end{array}$ \\
\hline 2011 & $\begin{array}{c}\text { Frequency } \\
\text { percent }\end{array}$ & $\begin{array}{c}20 \\
(6.4)\end{array}$ & $\begin{array}{c}105 \\
(33.45)\end{array}$ & $\begin{array}{c}80 \\
(25.5)\end{array}$ & $\begin{array}{c}64 \\
(20.4)\end{array}$ & $\begin{array}{c}40 \\
(12.8)\end{array}$ & $\begin{array}{c}5 \\
(1.5)\end{array}$ & $\begin{array}{c}314 \\
(100)\end{array}$ \\
\hline 2012 & $\begin{array}{c}\text { Frequency } \\
\text { percent }\end{array}$ & $\begin{array}{c}22 \\
(14.6)\end{array}$ & $\begin{array}{c}34 \\
(22.6)\end{array}$ & $\begin{array}{c}58 \\
(38.6)\end{array}$ & $\begin{array}{c}23 \\
(15.3)\end{array}$ & $\begin{array}{c}7 \\
(4.6)\end{array}$ & $\begin{array}{c}6 \\
(4)\end{array}$ & $\begin{array}{c}150 \\
(100)\end{array}$ \\
\hline 2013 & $\begin{array}{c}\text { Frequency } \\
\text { percent }\end{array}$ & $\begin{array}{c}21 \\
(10.5)\end{array}$ & $\begin{array}{c}43 \\
(21.5)\end{array}$ & $\begin{array}{c}85 \\
(42.5)\end{array}$ & $\begin{array}{c}28 \\
(14)\end{array}$ & $\begin{array}{c}15 \\
(7.5)\end{array}$ & $\begin{array}{l}8 \\
(4)\end{array}$ & $\begin{array}{c}200 \\
(100)\end{array}$ \\
\hline
\end{tabular}

The prevalence of substance consumption was $40.7 \%$ among women with either maternal or fetal cause's abortion. It was estimated that $78.3 \%$ belonged to cigarette and hookah, $14.62 \%$ to drug and psychotropic cases and finally $5.31 \%$ to alcohol beverage consumption (Table-3).

Table 3: Frequency distribution of Legal abortion according to history of use the certain substances

\begin{tabular}{|c|c|c|c|c|c|}
\hline $\begin{array}{c}\text { Use of special } \\
\text { materials }\end{array}$ & $\begin{array}{c}\text { Smoking \& } \\
\text { else }\end{array}$ & $\begin{array}{c}\text { Narcotics and } \\
\text { psychotropic pills }\end{array}$ & $\begin{array}{c}\text { Alcoholic } \\
\text { drinks }\end{array}$ & $\begin{array}{c}\text { Medical } \\
\text { drugs }\end{array}$ & \begin{tabular}{c} 
Total \\
\hline Frequency
\end{tabular} \\
Percent & 78.3 & 99 & 36 & 12 & 677 \\
\hline
\end{tabular}

The highest frequency was reported for alcoholic beverages consumption (7.7\%) in 2013 while other substances were the most frequent one in 2000. The highest prevalence of cigarette smoking was 82.2\% in 2000 (Table-4). 
Table 4: Frequency distribution of Legal abortion according to history of use the certain substances in couples since 2007 to 2013

\begin{tabular}{|c|c|c|c|c|c|c|}
\hline \multicolumn{2}{|c|}{ Use of materials } & \multirow{2}{*}{$\begin{array}{c}\text { Smoking \& } \\
\text { else }\end{array}$} & \multirow{2}{*}{$\begin{array}{c}\text { Narcotics and } \\
\text { psychotropic pills }\end{array}$} & \multirow{2}{*}{$\begin{array}{l}\text { Alcoholic } \\
\text { drinks }\end{array}$} & \multirow{2}{*}{$\begin{array}{c}\text { Medical } \\
\text { drugs }\end{array}$} & \multirow[t]{2}{*}{ Tota } \\
\hline & ear & & & & & \\
\hline \multirow[t]{2}{*}{2007} & Frequency & 42 & 15 & 3 & 1 & 61 \\
\hline & Percent & 68.85 & 24.6 & 4.9 & 1.65 & 100 \\
\hline \multirow[t]{2}{*}{2008} & Frequency & 25 & 18 & 4 & 1 & 48 \\
\hline & Percent & 52.1 & 37.5 & 8.3 & 2.1 & 100 \\
\hline \multirow[t]{2}{*}{2009} & Frequency & 84 & 20 & 4 & 1 & 109 \\
\hline & Percent & 77.06 & 18.35 & 3.6 & 0.91 & 100 \\
\hline \multirow[t]{2}{*}{2010} & Frequency & 120 & 20 & 4 & 2 & 146 \\
\hline & Percent & 82.2 & 13.7 & 2.73 & 1.4 & 100 \\
\hline \multirow[t]{2}{*}{2011} & Frequency & 82 & 8 & 5 & 2 & 97 \\
\hline & Percent & 84.5 & 8.25 & 5.15 & 2.06 & 100 \\
\hline \multirow[t]{2}{*}{2012} & Frequency & 80 & 10 & 7 & 2 & 99 \\
\hline & Percent & 80.8 & 10.1 & 7.1 & 2.02 & 100 \\
\hline \multirow[t]{2}{*}{2013} & Frequency & 97 & 8 & 9 & 3 & 117 \\
\hline & Percent & 82.9 & 6.85 & 7.7 & 2.6 & 100 \\
\hline
\end{tabular}

\section{Discussion}

In this retrospective study, an investigation was done on those referred to Fars forensic center to apply for abortion approval with maternal and fetal causes.

According to this seven-year survey, about 677(40.7\%) people, out of 1664 cases who referred to forensic centers, were addicted to cigarette, alcohol, drugs, and psychoactive substances. Also, the most prevalence was related to cigarette and hookah consumption. Floyd and colleagues reported drug abuse as the most remarkable factor which compromises both the health of pregnant women and their children in the UK. After alcohol, tobacco was reported as the second most common substance among pregnant women and elderly people.

Substance abuse, both before and during pregnancy period, was the predictor of prenatal drug consumption. The recommendation is to screen those mothers with either alcohol or cigarette consumption in women's primary health care to be identified as the high risk or endangered pregnant women who must be planned in advance [27] .
According to the next study which was done on 170 infants by mothers addicted to psychoactive substances during 1999-2008, the Poly drug abuse was associated with abortion history. In this study, no any addiction to cannabis and Poly drug was reported [28]. Young Norway Longitudinal Study investigated a possible link between abortion and dependence on nicotine, alcohol, cannabis and other drugs consumption between the ages of the 15-27 year during 11 years. Moreover, abortion occurrence was along with high rates of drug abuse and its related problems.

Alcohol and cannabis consumption were reduced in those who had pregnancies resulting in birth. The most prominent difference between these two studies was about the abortion permission which was obtained by means of maternal or fetal causes while substance abuse was not considered as an acceptable reason in this regard. This study didn't aim to examine the link between abortion and substance abuse [29]. According to available statistics, such as the United Nations Statistics Office on Drugs and Crime (UNODC) in 2003, an increase of changing consumption patterns from traditional opiate drugs (e.g. opium) into the 
synthetic substances was reported [30-32]. Despite the lack of accurate and exact statistics, according to some studies, $6 / 9 \%$ of the country's drug addicts are women.

Health department estimated the male/female ratio of addiction as 8/1 [33]. Also, because more women work outside home, they can easily have access to various drugs. Unlike the opium consumption which can cause laziness, women can use the substances such as a crack despite their active and energetic presence in the society. It's important to pay more attention and concern about fetal-maternal care and drug abuse prevention, treatment and control in the care before and during pregnancy [34].

In this study, diploma was the highest level of education (42/6 percent) and the rest were under diploma. According to the study which was conducted in 20002009, about 1008821 pregnant women were assessed; the average age of the mothers using addictive substances was less than non-users of drugs for 0.5-3 years. They were younger and less educated. More than 82 percent of the mothers had lower education (a primary or secondary school without a diploma) [13] .

Studies have shown the link between the education level and the decision to abort unwanted pregnancies. Abortion was reported more among low-literate women [35]. Substance abusing women have numerous social problems and limitations that illiteracy can be one of them. Therefore, it is important to explain the necessary information to the women (and spouses or sexual partners) in writing and verbal form to ensure that the information is understood [36].

Giving information and advice about the drug complications may not be the only sufficient intervention for drug-dependent pregnant women. Also, it can't encourage her to seek further consultations and treatments. The appropriate therapeutic relationship between the staff and pregnant women causes them to feel confident in the pregnancy care workers. This confidence leads to constant treatment.

\section{Conclusion}

This seven-year survey on women with legal abortion authorization under fetal-maternal causes indicates that $40.7 \%$ had substance dependency. Among them, cigarette and hookah consumers were the most. Although the association between fetus abortion and its related causes is not examined in this study, it's important to pay more attention and concern about fetal-maternal care and drug abuse prevention, treatment and control in the care both before and during pregnancy

Acknowledgements: This article was extracted from the research proposal approved by Student Research Committee of Shiraz University of Medical Sciences (proposal No.7745) the authors would like to thank the Student Research Committee of Shiraz University of Medical Sciences for financially supporting this research. The authors would like to thank Shiraz University of Medical Sciences, Shiraz, Iran and also Center for Development of Clinical Research of Nemazee Hospital and Dr. Nasrin Shokrpour for editorial assistance.

Funding: Nil

Conflict of interest: None.

Permission of IRB: Yes

\section{References}

1. Ahmadi B, Farzadi F, Alimohammadian M. (2012). Women's health in Iran: issues and challenges. Payesh, 1(1):127-137. (Persian)

2. Alyaemni A, Theobald S, Faragher B, Jehan K, Tolhurst R. (2013). Gender inequities in health: an exploratory qualitative study of Saudi women's perceptions. Women Health; 53(7):741-59. doi: 10.1080/03630242.2013.829169.

3. Ellertson C, Elul B, Ambardekar S, Wood L, Carroll J, Coyaji K. Accuracy of assessment of pregnancy duration by women seeking early abortions. Lancet 2000 Mar 11;355(9207):877-81. PMID:10752703

4. Mawdsley SD1, Baskett TF. Outcome of the next labour in women who had a vaginal delivery in their first pregnancy. BJOG. 2000 Jul;107(7):932-4. PMID:10901567

5. Rafraf M, Mahdavi R, Milani Sh, Mahboob SA. [Assessment of some effective factors on the weight gain during pregnancy and birth weight of newborns] [Article in Persian]. J Tabriz Univ Med Sci 2002;55:317.

6. Płotka J1, Narkowicz S, Polkowska Z, Biziuk M, Namieśnik J.Effects of addictive substances during pregnancy and infancy and their analysis in biological 
materials .Rev Environ Contam Toxicol. 2014;227:5577.

7. Konijnenberg $\mathrm{C} 1$. Methodological Issues in Assessing the Impact of Prenatal Drug Exposure. Subst Abuse. 2015 Nov 8;9(Suppl 2):39-44. doi: 10.4137/SART.S23544

8. United Nations Office against Drugs and Crime. World Drug Report 2011. (2011). available https://www.unodc.org/unodc/en/data-andanalysis/WDR-2011.html

9. Broussard CS, Rasmussen SA, Reefhuis J, et al: Maternal treatment with opioid analgesics and risk for birth defects. Am J Obstet Gynecol. 2011; 204(4):314e1-314e11.

doi.org/10.1016/j.ajog.2010.12.039

10. Rahimi mogher A. Prevalence and patterns of drug use and addiction among women in Iran. Social Welfare (Iranian Women's pathology): 2004; 3, (12): 203 - 226.

11.Torshizi M, Saadatjoo S, Farabi M. Prevalence of narcotic substance abuse and the maternal and fetal outcomes in pregnant women. jjums. 2011; 9 (3) :14-19. http://jmj.jums.ac.ir/browse.php?a_code=A-10-1-

$75 \&$ slc_lang $=$ en\&sid $=1$, http://www.socialwork2012.ir/?p=841

13. Nechanská B1, Mravčík V, Sopko B, Velebil P. [Pregnant women and mothers using alcohol, tobacco and illegal drugs]. Ceska Gynekol. 2012 Oct;77(5):45769.[Article in Czech] PMID:23116352

14. Narkowicz S, Płotka J, Polkowska Ż, Biziuk M, Namieśnik J. Prenatal exposure to substance of abuse: a worldwide problem. Environ Int. 2013 Apr;54:141-63. doi: 10.1016/j.envint.2013.01.011. Epub 2013 Feb 27.

15. Keegan J1, Parva M, Finnegan M, Gerson A, Belden M. Addiction in pregnancy. J Addict Dis. 2010 Apr;29(2):175-91. doi: 10.1080/10550881003684723.

16. Cunningham FG, Kenneth JL, Steven LB, John CH, Dwight JR,Catherine YS. Williams obstetrics, Parkland Hospital.23rd edition. New York: McGraw-Hill; 2010.

17. Grella CE, Hser YI, Huang YC. Mothers in substance abuse treatment: differences in characteristics based on involvement with child welfare services. Child Abuse Negl 2006 Jan30(1):55-73. PMID:16406024
18. Rahi E, Baneshi MR, Mirkamandar E, Haji Maghsoudi S, Rastegari A. A Comparison between APGAR Scores and Birth Weight in Infants of Addicted and Non-Addicted Mothers. Addict Health. 2011 Winter-Spring;3(1-2):61-7. PMCID: PMC3905520

19. Roberts SC1, Avalos LA, Sinkford D, Foster DG.Alcohol, tobacco and drug use as reasons for abortion. Alcohol Alcohol. 2012 Nov-Dec;47(6):640-8. doi: 10.1093/alcalc/ags095. Epub 2012 Aug 22.

20. Lassi ZS, Imam AM, Dean SV, Bhutta ZA. Preconception care: caffeine, smoking, alcohol, drugs and other environmental chemical/radiation exposure. Reprod Health. 2014 Sep 26;11 Suppl 3:S6. doi: 10.1186/1742-4755-11-S3-S6. Epub 2014 Sep 26.

21. Roberts SC, Avalos LA, Sinkford D, Foster DG.Alcohol, tobacco and drug use as reasons for abortion. Alcohol Alcohol. 2012 Nov-Dec;47(6):640-8. doi: 10.1093/alcalc/ags095. Epub 2012 Aug 22.

22. Sharifian J, Jahanian M, Tavassoli F, Tavassoli S, AfzalAghaee M, Afshari R, et al . [The fate of motherhood,fetuses and neonates in drug addicted pregnant women] [Article in Persian]. J Shahid Beheshti Univ Med Sci 2011;19(2):183-91.

23. De Santis M, De Luca C, Mappa I, Quattrocchi T, Angelo L, Cesari E. Smoke, alcohol consumption and illicit drug use in an Italian population of pregnant women. Eur J Obstet Gynecol Reprodu Biol 2011 Nov;159(1):106-10. doi: 10.1016/j.ejogrb.2011.07.042. Epub 2011 Aug 9.

24. Atrak H. Philosophical reasons for abortion or not. Ethics and History in Medicine J. 2008; 1(3): 55-64. [Persian]

25. Akhavan S. Case report: A criminal abortion with uterus perfovation. Scientific Journal of Kurdestan University of Medical Sciences. 1998; 9(3): 35-7.

26. Behjati Ardakaniz, Akoondi MM, Sadeghi MR,Sadri Ardekani H. The necessity of a comprehensive study on abortion in Iran. Medical Journal of Reproduction and Infertility. 2005;24(6): 299-320.

27. Floyd RL, Jack BW, Cefalo R, Atrash H, Mahoney $\mathrm{J}$, Herron A, etal. The clinical content of preconception care: alcohol, tobacco, and illicit drug exposures. Am J 
Obstet Gynecol. 2008 Dec;199 (6 Suppl 2):S333-9. doi: 10.1016/j.ajog.2008.09.018

28. Simmat-Durand L1, Toutain S, Vellut N, Genest L, Crenn-Hebert C, Simonpoli AM, etal. [Maternal and obstetrical data in a retrospective cohort of 170 newborns from polydrug using mothers, in the Paris area, 1999-2008]. J Gynecol Obstet Biol Reprod (Paris). 2010 Dec;39(8):647-55. doi: 10.1016/j.jgyn.2010.06.013. Epub 2010 Aug 13.

29. Pedersen W. Childbirth, abortion and subsequent substance use in young women: a population-based longitudinal study. Addiction. 2007; 102(12):1971-8. PMID:18031432

30. United Nations Office On Drug and Crime. Epidemiology of drug use in Iran. 2007.Available from:http://www.unodc.org/iran/en/epidemiology.html2 010 [cited $201011 \mathrm{Feb}$ ].

31. Sandeep C. World drug report 2011.United Nations Publication:United Nations Office On Drugs and Crime(UNODC); 2011.
32. Jafari S, Rahimi Movaghar A, Baharlou S, Kevin JP. Trends of substance use in southern Iran: a qualitative study. Int $\mathrm{J}$ Eepidemiol 2008;6(1). ol:10.5580/12a8. http://ispub.com/IJE/6/1/7802

33.. Poorasgar N.Medical Information.Available from: htpp:// www.nimapoorasgar.blogfa.com. http://rhodium.blogsky.com/page-211

35. Uygar D. Erkaya S. Reasons Why women have induced abortions in a developing Cpuntry .European Journal of Obstetrics and Gynecology and Reproductive Biology. 2001; 96: 211-4.

36. Guidelines for the management of drug dependence in pregnancy, Birth (childbirth), lactation and infancy. Office of Mental Health, Social and addiction Department of prevention, Health Deputy Minister of Health and Medical Education of Iran.avalible: treatment.sbmu.ac.ir/uploads/Dependency_Management _Guide.pdf

\section{How to cite this article?}

Ghodrati F, Saadatmand N, Zarenezhad M, Akbarzadeh M, A seven-year study about the epidemiology of smoking, alcohol, drugs and psychotropic consumption along with legal abortion in cases referred to forensic medicine centers in Fars since 2007-2013. Int J Med Res Rev 2016;4(3):424-431. doi: 10.17511/ijmrr.2016.i03.25 